\title{
Becoming a "Science Person": Faculty Recognition and the Development of Cultural Capital in the Context of Undergraduate Biology Research
}

Jennifer Jo Thompson ${ }^{\text {** }}$ and Danielle Jensen-Ryan ${ }^{*}$

'Department of Crop and Soil Sciences, University of Georgia, Athens, GA 30602; 'Department of Anthropology, University of Wyoming, Laramie, WY 82071

\begin{abstract}
We argue that cultural capital plays an underexamined role in students' recognition as budding scientists by faculty. By triangulating interview data from undergraduates and faculty mentors in a multi-institutional biology research network, we identified a set of intersecting domains of capital that help render students recognizable to faculty. We argue that faculty recognition often reflects a (mis)alignment between the cultural capital that students possess and display and what faculty expect to see. To understand why misor underrecognition occurs, and how this influenced students' opportunities to further develop cultural capital, we explored our data set for patterns of explanation. Several key themes cut across students' experiences and influenced their recognition by faculty: Faculty more easily recognized students interested in research science trajectories and those involved in institutional programs to support science, technology, engineering, and mathematics success. Students with competing family responsibilities struggled to maintain faculty recognition. Finally, faculty who broadened their scopes of recognition were able to affirm the science identities of students with fewer incoming cultural resources in science and support their development of capital. Students can and do develop scientific cultural capital through practice, but this requires access to research and mentorship that explicitly teaches students the implicit "rules of the game."
\end{abstract}

\section{INTRODUCTION}

Participation in undergraduate research is thought to develop students' science identities (Carlone and Johnson, 2007; Estrada et al., 2011). Science identity has been defined in a number of ways, but as a whole, this work emphasizes 1) an internal sense of oneself as a scientist or "science person" and 2) the recognition of that sense of self in a social context, especially by "meaningful" or "relevant" others like professors, teachers, mentors, and peers (Brickhouse et al., 2000; Gee, 2000; Carlone and Johnson, 2007; Carlone et al., 2011; Hurtado et al., 2009b; Hazari et al., 2013; Trujillo and Tanner, 2014). Science identities are not fixed, but are trajectories with some consistency that can shift directions over time (Brickhouse et al., 2000; Carlone et al., 2014; Gazley et al., 2014). Nevertheless, science identity is a good predictor of whether students (especially those from underrepresented groups) persist in science, technology, engineering, and mathematics (STEM) careers (Carlone and Johnson, 2007; Shanahan, 2008; Archer et al., 2010; Chang et al., 2011; Chemers et al., 2011; Espinosa, 2011; Hazari et al., 2013).

The science identity literature reflects a number of theoretical orientations that together emphasize the way science identities are socially situated, constructed through day-to-day practice, and affirmed by social recognition (Lave and Wenger, 1991; Carlone et al., 2011; Calabrese Barton et al., 2013; Tan et al., 2013). Through practice, students develop knowledge and skills that help them do science, but they
Jeff Schinske, Monitoring Editor Submitted Nov 8, 2017; Revised Sep 14, 2018; Accepted Sep 17, 2018

CBE Life Sci Educ December 1, 2018 17:ar62 DOI:10.1187/cbe.17-11-0229

*Address correspondence to: Jennifer Jo Thompson (jjthomp@uga.edu).

(c) 2018 J. J. Thompson and D. Jensen-Ryan. CBE-Life Sciences Education ( 2018 The American Society for Cell Biology. This article is distributed by The American Society for Cell Biology under license from the author(s). It is available to the public under an Attribution-Noncommercial-Share Alike 3.0 Unported Creative Commons License (http://creativecommons.org/ licenses/by-nc-sa/3.0).

"ASCB®" and "The American Society for Cell Biology ${ }^{\circledR}$ " are registered trademarks of The American Society for Cell Biology. 
are also "forging identities" about what it means to be a scientist (Lave, 1991; Brickhouse et al., 2000; Hunter et al., 2007). At the same time, these identities are being performed for others-including their faculty mentors, who may or may not recognize and affirm students' science identities (Hurtado et al., 2009a).

In this paper, we expand on the seminal work by Carlone and Johnson (2007) to theorize and operationalize undergraduates' recognition by faculty research mentors-a key group of "meaningful others." Through richly contextualized qualitative research with students and faculty participating in a distributed research network, we examine how faculty recognition occurs in the context of undergraduate research. Using social theorist Pierre Bourdieu's concept of "cultural capital" (1997), we argue that faculty recognition is facilitated by students' cultural capital in science, and that faculty recognition in turn facilitates students' access to greater opportunities to build scientific cultural capital. We posit that faculty recognition and cultural capital operate in a positive feedback loop with consequences for students who do not enter science with the expected or immediately recognizable forms of cultural capital, and we argue that faculty can support these students by expanding their scopes of recognition.

\section{THEORETICAL FRAMEWORK: CULTURAL CAPITAL}

Bourdieu's original conceptualization of cultural capital sought to explain the social mechanisms that reproduce entrenched class inequalities. He defined cultural capital as one's set of cultural resources (one's qualifications, as well as one's "long lasting dispositions of the mind and body" [1997, p. 47]) that facilitate access and mobility within a social context, or field. ${ }^{1}$ According to Bourdieu's theory, early "enculturation" through repeated and extended exposure and participation (in education, the arts, sports, or in this case, science) leads to a deeply embodied (and often unspoken) understanding of the "rules of the game" (Bourdieu and Wacquant, 1992), such that a desire to play, confidence to join the game, skill at play, and then recognition by others as a good player all appear to come naturally. This underscores a key tension with regard to cultural capital: whether it reinforces the cultural reproduction of social inequalities by reifying the social order, or whether it can be a resource for social mobility.

Researchers have adopted many and various approaches to cultural capital in the context of education research. Cultural capital has been posited as a partial explanation for the "achievement gap" observed across race/ethnicity and class (e.g., DiMaggio, 1982; Lareau, 1987; Bourdieu and Passeron, 1990; Dumais, 2002; Lee and Bowen, 2006; Jæger, 2011). Researchers have examined how exposure or participation in "high culture" (e.g., fine arts, symphony, opera) and reading relates to academic

\footnotetext{
${ }^{1}$ Bourdieu (2004) emphasizes that cultural capital is specific to the field. Thus, the kinds of cultural capital with the greatest value (i.e., which knowledge and skills, which attitudes and comportments, and the specific rules of the game that afford social mobility) is highly contextual. Carter (2003), for example, examines cultural capital among low-income African-American youth, emphasizing that nondominant cultural capital operates in ways analogous to dominant cultural capital: to enact status position, afford or restrict social mobility, and define social boundaries of the group (or field). Importantly, there is interplay in the forms of capital that have currency across fields.
}

achievement (e.g., DiMaggio, 1982; Gaddis, 2013), finding support for the relationship between cultural capital and academic achievement and for the cultural reproduction of inequality (Roscigno and Ainsworth-Darnell, 1999; Jæger, 2011). Yet, some studies find that exposure to and participation in activities that are traditional markers of cultural capital can also enable access and mobility within a narrow social field (DiMaggio, 1982; DeGraff et al., 2000; Dumais, 2006).

Science education researchers have used cultural capital as a lens for understanding disparities in science persistence (e.g., Aikenhead, 1995; Brickhouse, 2001; Adamuti-Trache and Andres, 2008; Archer et al., 2012, 2014, 2015; Claussen and Osborne, 2013; Gazley et al., 2014; Thompson et al., 2016) and have shown that cultural capital can powerfully impact the degree to which students consider futures in science "thinkable" (Archer et al., 2012, 2014; Gazley et al., 2014). In research focused on elementary school students in the United Kingdom, Archer et al. (2012) found that families that have embedded science into family life, whether as a result of family members' own interest and careers in science or through "concerted cultivation" (Lareau, 2003) of science in the household, more effectively foster and support scientific aspirations among their children.

Archer and colleagues (2012, 2014, 2015) have proposed the term "science capital" to refer collectively to "science-related forms of cultural and social capital" (2015, p. 922). In an effort to develop a theoretical model of science capital, Archer et al. found that science capital largely aligns with the measures they used to operationalize cultural capital in science: scientific literacy (knowledge, skills, and the ability to apply them), scientific-related dispositions and practices (recognizing the value of science in society and having a positive attitude toward science), and a recognition of the value of scientific skills and credentials in the labor market (Archer et al., 2015).

In prior work, J.J.T. and colleagues examined cultural capital as one of several forms of capital that undergraduates draw on to access research opportunities and develop in the context of research (Thompson et al., 2016). They described an overlapping set of resources: human capital, described as technical skills and knowledge, or "what you know"; cultural capital, an enculturated set of norms, values, and dispositions, or "how you know"; and social capital, interpersonal connections that provide access to resources and information, or "who you know." That work examined the ways that undergraduates draw upon various forms of capital to access research experiences and how research experiences help undergraduates expand their capital, in the form of knowledge and skills, social ties with peers and mentors, and a scientific mind-set and disposition (Thompson et al., 2016). Importantly, these forms of capital are not distinct entities; rather, they "constitute an overlapping set of resources" and "the distinctions between forms of capital are, to some degree, a heuristic for deconstructing the range of resources students may develop and deploy through their participation in a research network" (Thompson et al., 2016, p. 966).

In this paper, we disaggregate what cultural capital looks like in the context of undergraduate biology research-with an emphasis on the experiences of students from underrepresented groups and first-generation college students. Following Bourdieu (2004) and Lareau and Weininger (2003), we argue that what constitutes cultural capital is specific to the field, or 
even the subdiscipline. Thus, although our work is informed by prior work on the development of science-related capital, we largely take a ground-up approach to characterizing cultural capital. In other words, rather than imposing arbitrary limitations on the definition of cultural capital from the outside, we sought to identify the set of cultural resources that render undergraduates recognizable to faculty.

Importantly, we do not employ a cultural capital lens to reify deficit thinking about the potential of students from underrepresented groups. Rather, we align our thinking with Lareau and Weininger (2003), who critically frame cultural capital as a resource by which the powerful control privileged access to opportunities. Those authors argue that this plays out in education as a mismatch between the expectations of educators and the access of students and parents to the cultural resources needed to meet these expectations. We draw upon interviews with undergraduates and their faculty research mentors to argue that cultural capital plays an undertheorized role in whether and how students are recognized by faculty, and through this work we aim to encourage faculty to broaden their recognition of and support for students who may not initially demonstrate the expected forms of scientific cultural capital.

\section{METHODS \\ Data Collection}

This study is part of a longitudinal, ethnographic study of a multi-institutional biology research network (2011-2016). This research network began in 2011 as an interdisciplinary collaboration among five faculty at three primarily undergraduate institutions. By the time of our research in 2015-2016, the research network had expanded to 12 faculty supervising undergraduate research internships at 10 institutions-including research-intensive, primarily undergraduate, 2-year community college, and minority-serving institutions in the United States and Canada. ${ }^{2}$ The scientific objectives of the research network are to study the phenotypic changes in a model plant species resulting from disabling individual genes. This paper focuses on the experiences and development of students participating in project-related research internships, in which undergraduates work with faculty, graduate students, and peers within the faculty member's research lab. Because these students performed similar scientific tasks based on shared experimental and data-collection protocols across the biology research network, we are well positioned to examine the variation in science identity and cultural capital among students, as well as why some students received faculty recognition when others did not. The network provided us with a shared foundation to compare students' experiences with research and recognition.

\footnotetext{
${ }^{2}$ Although this study focuses on the experiences of students participating in research internships, a number of the faculty involved in this project also ran course-based undergraduate research experiences (CUREs) related to this research project. Several faculty described using the CUREs as a recruitment opportunityand particularly, they describe identifying students who excel in CUREs to recruit for research internships, even if they do not excel in typical lecture/lab courses. Thus, although this point is beyond the scope of our current project and manuscript, we posit that CUREs may also be a way for faculty to expand their scopes of recognition beyond students who possess the cultural capital to seek out research internships in the first place. Faculty and institutions running only CUREs (no research internships) are excluded from this analysis.
}

This study was approved by the University of Georgia's Institutional Review Board, and all participants provided informed consent. All names have been replaced by pseudonyms, with pseudonyms beginning with an $\mathrm{F}$ for faculty members and $\mathrm{S}$ for undergraduate students.

\section{Interviews}

We collected our data through interviews, conducted by phone, Skype, or in person during project meetings and site visits. In this paper, we analyze data collected in interviews with undergraduates and faculty participating in the research network between 2015 and 2017. We also capitalized on the longitudinal nature of this project by drawing on data collected in earlier waves of interviews with students and faculty (in 2011-2014) to interrogate and corroborate our analyses,

Student Interviews. We conducted open-ended, semistructured interviews with undergraduates to disaggregate what culture capital looks like in this biology research network. To ensure an in-depth and nuanced understanding of cultural capital across diverse undergraduate experiences, we deliberately oversampled students from demographic groups underrepresented in science. In late 2015, we invited (via email) all current student-researchers who self-identified as an underrepresented minority (African American, Hispanic/Latinx, or Native American) or first-generation college student (based on parents' education level) to participate in interviews. ${ }^{3}$ Ten of the 18 invited students completed interviews by phone, in person, or at an all-institution project meeting in the summer of $2016 .{ }^{4}$ To broaden our sample, we verbally invited students attending the project meeting to participate in interviews, and we extended personal invitations to students from institutions that were not yet represented in our sample. This resulted in 10 additional interviews with students who did not self-identify as members of an underrepresented minority or first-generation college student. In the end, we interviewed 20 students from 10 institutions, with seven (35\%) students identifying as members of an underrepresented minority group and eight (40\%) as first-generation college students. Eighty percent $(n=16)$ of our sample was female. Table 1 provides the demographics of student interviewees.

Student interviews, conducted by J.J.T. and an undergraduate research assistant, consisted of three major sections: 1) precollege exposure to science and early science identity, 2) experience of participating in undergraduate research, and 3) science identity and practice at the college level. (See student interview guide in the Supplemental Material.) The interview structure provided a framework to guide the conversation, but allowed participants to identify and prioritize the experiences,

\footnotetext{
${ }^{3}$ To collect demographics of students participating in research internships within the network and to help guide our qualitative data collection, we surveyed all students who participated in the network from its initiation through student interview recruitment in Fall 2015

${ }^{4}$ This was a National Science Foundation (NSF)-funded all-institution project meeting. Faculty were each invited to bring two students who had worked on the project to participate in the meeting. The objective in including undergraduates was provide them with the opportunity to learn more about the project as a whole, present a poster focused on their research, and network with students and faculty across all institutions. Faculty were not given criteria for selecting students to participate in the meeting.
} 
TABLE 1. Multi-institutional biology research network student interviewee demographics

\begin{tabular}{lc}
\hline Student interviewees $(\boldsymbol{n = 2 0 )}$ & Number (\%) \\
\hline Gender & \\
Female & $16(80)$ \\
Male & $4(20)$ \\
Race & \\
White & $12(60)$ \\
Black or African American ${ }^{\mathrm{a}}$ & $5(25)$ \\
Asian & $2(10)$ \\
Prefer not to respond & $1(5)$ \\
Ethnicity & \\
Non-Hispanic/Latinx & $18(90)$ \\
Hispanic Latinx & \\
Parents' maximum education level & $2(10)$ \\
Doctoral degree (PhD/JD/MD) & \\
Master's degree (MA/MS) & $1(5)$ \\
Bachelor's degree (BA/BS) & $4(20)$ \\
Some college (no degree) & \\
Technical school & $7(35)$ \\
High school or GED & $5(25)$ \\
Institution type & $2(10)$ \\
Research-intensive university & $1(5)$ \\
Primarily undergraduate institution & \\
Historically Black college/university & \\
Two-year institution or community college & $5(25)$ \\
\hline
\end{tabular}

${ }^{\mathrm{a} C a t e g o r i z e d ~ a s ~ a ~ m e m b e r ~ o f ~ a n ~ u n d e r r e p r e s e n t e d ~ m i n o r i t y ~ g r o u p . ~}$

${ }^{\mathrm{b} C}$ Categorized as a first-generation college student.

opportunities, and relationships that mattered most to them. Understanding students' self-recognition, their accounts of being recognized by others, and their emergent cultural capital would not have been accessible via another method, such as observation or surveys alone. Each student interview lasted approximately 45-60 minutes. After each interview, the interviewer made detailed notes, including the context and content of the interview and connections to issues of theoretical interest (e.g., science identity and related cultural capital). All interviews were audio-recorded and transcribed verbatim, with the exception of one, due to equipment failure. Students received $\$ 10$ gift cards as compensation for participation.

Faculty Interviews. To further understand undergraduates' science identity and development of cultural capital, we collected data about undergraduate students through in-person and Skype interviews with faculty members in 2016. Table 2 describes the demographics and institutional characteristics of the 11 faculty interviewed from 10 institutions. (Despite several requests, we were unable to schedule an interview with one faculty member.)

The objective of faculty interviews was twofold: 1) to understand the faculty's approach to undergraduate research (within the biology research network, in particular) and 2) to examine faculty recognition of the science identities of undergraduates in their labs. (See faculty interview guide in the Supplemental Material.) Faculty interviews, conducted by D.J.-R., included a card-sorting activity: faculty were presented with index cards
TABLE 2. Multi-institutional biology research network faculty interviewee demographics

\begin{tabular}{ll}
\hline Faculty interviewees $(\boldsymbol{n}=\mathbf{1 1})$ & Number (\%) \\
\hline Gender & \\
Female & $7(64)$ \\
Male & $4(36)$ \\
Institution type & \\
Research-intensive university & $3(27)$ \\
Primarily undergraduate institution & $5(55)$ \\
Historically Black college/university & $1(9)$ \\
Two-year institution or community college & $2(27)$ \\
\hline
\end{tabular}

for each of their students who participated in a network research internship and they were asked to group the cards according to a number of factors (students for whom they had written recommendation letters, who continued to graduate school, who were particularly successful, who stood out as leaders in the lab, who had difficulty in the lab, who contributed in unexpected ways, etc.). Although this activity was useful for identifying specific ways that students accessed and drew upon cultural capital, it was especially valuable as a prompt for faculty to reveal how they defined student success and how they valued students' contributions to research. Faculty interviews also allowed us to compare faculty recognition with students' own perceptions of their science identities. Each interview lasted approximately 60-120 minutes. After each, the interviewer made detailed notes, including the context and content of the interview and connections to issues of theoretical interest (e.g., students' science identity as well as cultural capital). All interviews were audio-recorded and transcribed verbatim.

\section{Data Analysis}

Our qualitative analysis protocol began with a review of the interview transcripts for accuracy before they were imported into Atlas.ti (qualitative data management software, Scientific Software Development $\mathrm{GmbH}$ ) for analysis. Once this material was uploaded into Atlas.ti, we systematically read and indexed each interview. We began indexing interviews using a preliminary list of "codes" representing our research objectives and themes in the literature on science identity (e.g., self-recognition, and recognition by scientific and nonscientific others; as well as positive, negative, and little/no recognition, following Carlone and Johnson [2007]) and cultural capital (e.g., family science background, attitudes and exposure to science, access to and exclusion from scientific activities, and participation in scientific activities and discourse, following Bourdieu [1997, 2004]; Lareau and Horvat [1999]; Archer et al. [2015]). Throughout our analysis, we remained open to identifying new themes not represented in our initial code list (Glaser and Strauss, 1965; Charmaz, 2006; Suddaby, 2006). When encountering new themes (e.g., peer recognition, religious identity), we discussed how they related to our research questions and whether they were already represented by existing codes or warranted addition to the code list. We added codes, refined code definitions, collapsed code categories, and recoded interviews to reflect the data and to ensure consistency in our analysis (Saldaña, 2009). To ensure validity of our analysis, the 
interviews were coded by D.J.-R. and cross-checked for accuracy by J.J.T. We met regularly to discuss areas of conceptual ambiguity that we flagged during coding and resolve discrepancies between coders. Our code list and definitions stabilized after coding and discussing approximately half of the student and faculty interviews.

The final code list for student interviews included codes (and subcodes) related to science identity, other forms of identity, motivations for doing science, participation in the biology research project, active and passive development of science-related cultural capital, and access to/use of various forms of capital. The code list for faculty interviews paralleled the student interview code list, with minor variations, and additional codes to broadly capture faculty experiences and their roles within the research network. We also included codes to index faculty data about each student. (See student and faculty codes and subcodes in the Supplemental Material.)

After coding the interview data, we systematically compared student data with faculty data: we compared students' self-recognition with faculty recognition of students' identities as scientists, and how students characterized their research experiences alongside faculty assessments of students' performance and contribution to the project. This allowed us to identify areas of alignment and misalignment between students' self-perception and faculty recognition. At this point, we compared cases across the data set to identify patterns in the data that would help us make sense of these areas of (mis)alignment. We used a lens of cultural capital to identify the cultural resources that rendered students "recognizable" (or not) to faculty. (See "Cultural Capital Domain Rubric," which includes exemplar quotes from across our data set, in the Supplemental Material.) We also triangulated these findings with data collected in earlier stages of the research to further interrogate and corroborate our interpretations. In particular, we reviewed our field notes and examined transcripts from previous interviews for data related to students that faculty named as particularly successful (or not) to investigate how these students characterized their experiences with research, their relationships with their research mentors, and to see how these students were characterized by other students (e.g., as leaders, collaborators). Our complementary research positionalities (J.J.T. had longitudinal experience with the research network and D.J.-R.brought a fresh set of eyes to the project) encouraged critical engagement with the data. Our systematic coding process in Atlas.ti, combined with our comparison of longitudinal data in the biology research network, ensured a robust qualitative analysis of students' undergraduate research experiences, with an emphasis on the experiences of students from underrepresented groups.

\section{Generalizability}

Our findings are grounded in context-rich, longitudinal research with a distributed network. This allowed us to investigate the relationship between students' science-related cultural capital and faculty recognition over time and across institutional contexts. A strength of in-depth, qualitative research like this is its potential for naturalistic and inferential generalizability, meaning that our research findings may resonate with the lived experiences of our readers, who may be able to apply our results to other contexts (Stake, 1995; Ritchie and Lewis, 2003; Smith, 2018). It is not our objective to make claims about the statistical generalizability of our findings, in terms of their prevalence or distribution in a population. As Donmoyer (2000) has argued, thinking of generalizability "solely in terms of sampling and statistical significance is no longer defensible or functional" (p. 46). In contrast, we believe that our findings have inferential generalizability for many faculty members mentoring undergraduate researchers, and we provide a high level of rich, deeply contextualized, evidence (in the form of vignettes selected to illustrate the maximum variability of our sample) to allow readers to determine the degree to which our findings are transferable to their own context.

Our research is aimed not at identifying universals that govern faculty-student relationships, but at understanding a phenomenon in context. However, we argue, following Flyvbjerg (2006), that context-rich qualitative research with strategically selected cases is well suited to break new theoretical ground. Having examined faculty-student relationships over time and across a number of institutions within this distributed research network, we suggest that our observations about the relationship between faculty recognition and the development of scientific cultural capital may have broader analytical generalizability. We encourage further research in this area.

\section{RESULTS AND DISCUSSION}

We were interested in what cultural capital looks like in the context of undergraduate biology research, and how differences in students' cultural capital impact their recognition from faculty. Through our analysis of interviews with students and their faculty research mentors, we identified a set of intersecting cultural resources that help to render undergraduates recognizable to faculty. In the process, we identified a powerful feedback loop between faculty recognition and cultural capital in the context of undergraduate research.

Students who embodied the forms of cultural capital and scientific dispositions familiar to their faculty mentors were easily recognized and rewarded with increased opportunity to practice and develop more cultural capital in science. This, in turn, opened doors to opportunities for these students to put their capital to use by identifying and accessing unique opportunities to expand their participation in science. Faculty recognition also served to reinforce these students' personal sense of themselves as "science people." In short, these students experienced a good fit between their scientific dispositions and the expectations of the field.

In contrast, other undergraduates had fewer scientific cultural resources to draw upon. When these students' initial science-related attitudes, tastes, or practices did not align with the expectations of faculty, they were more likely to be mis- or underrecognized. In turn, these students had fewer opportunities to build cultural capital in scientific spaces and struggled to persist in careers in science. Importantly, we found evidence that faculty can make a powerful difference by expanding their scope of recognition to affirm students' interest in science and mentor them through learning the implicit "rules of the game." This provides a broader range of students with an opportunity to acquire and practice the attitudes and dispositions familiar to the fieldkey facets of cultural capital that foster faculty recognition.

We present our results through a series of vignettes—detailed cases strategically selected from our interviews with students and faculty to illustrate maximum variation and patterns in our 
sample overall (Flyvbjerg, 2006). Rather than presenting a series of decontextualized quotes from student and faculty interviews, we demonstrate the complex relationships between students' cultural capital and faculty recognition with a level of rich detail that both brings these cases to life and acknowledges that context matters when it comes to understanding and interpreting human experience and interaction. The vignettes are real cases from our data, and they should not be read as representing discrete categories of students. As such, we do not make claims about their prevalence in our sample. Our objective is to provide examples from our data that may resonate with faculty, so that they can exercise the practical applications of this research (e.g., recognizing students' emerging interest and self-recognition as scientists and supporting their development of cultural capital in the field).

Each vignette begins with the student's perspective on his or her science trajectory, followed by the faculty perspective of the student, and a brief explication of the cultural capital that students draw upon to construct their identities as scientists, access research, engage in scientific practice, and ultimately render themselves recognizable to faculty mentors. We summarize the key domains of science-related cultural capital that influence faculty recognition and present four prominent themes that emerged as particularly influential to understanding faculty recognition in this data set.

\section{Vignette 1: Recognizing Cultural Capital through Research Interest}

Student Perspective: Sadie. Sadie, a white student, identified as a "science person" with a love of science beginning early in her life and hopes to follow in her father and brother's footsteps (both are computer scientists) working in a science-related field. She learned of the biology research network through her participation in a midlevel biology course focused on materials from the research network, which she "thoroughly enjoyed" (both scientifically and socially). Owing to her positive experience in the course, Sadie approached Dr. Fiona to inquire whether she could join her lab and was quickly admitted.

She found her research in the lab setting particularly gratifying, as it was "super exciting when you finally figure something out!" Like most undergraduate students at her primarily undergraduate college, Sadie has a close relationship with Dr. Fionaher primary "mentor" (as Sadie describes her) for not only scientific purposes, but also with regard to her undergraduate tenure and life goals. The strong bond between Dr. Fiona and Sadie led Dr. Fiona to ask Sadie to work with her (the only student asked) on an outreach program to "bring science to children." Sadie also relayed how Dr. Fiona is more than just an academic advisor, as she calls on Dr. Fiona to help her with the "rest of her life."

Sadie discussed how she understood her time at college was meant to build relationships and research skills so that she could forge ahead in graduate school. (She has since graduated from her institution and is currently pursuing a $\mathrm{PhD}$ in a science-related career.) During our interview, Sadie relayed a deep understanding of the graduate application process by stating, "I only applied to three [institutions] because you have to find a lab that you're interested in working in, get in contact with that person, they have to be interested in you, and then you apply." Her future career plans are to pursue "research" or a "museum job."
Faculty Perspective: Sadie. When asked which students excel academically, Dr. Fiona is quick to discuss Sadie. Though Dr. Fiona acknowledged her response to students' "success" as a "very traditional way of looking at success," she discussed how Sadie is "in the graduate program" of her choice-a "high-quality program" in which Sadie is "succeeding thus far." Dr. Fiona stated how she thinks she "directly helped her [Sadie] get into graduate school.” As Dr. Fiona noted,

She's the first one really to go into the field very close to what I do ... So I was like who do you want to work with? Maybe you should think about this person, this person, this person. And actually it was somebody that Felicia [another faculty member in the research network] worked with for a period of time that Sadie is now doing her $\mathrm{PhD}$ with.

Dr. Fiona further identified Sadie as a "leader" who emerged in the lab due to her "confidence" and how she "had the skills to go behind" her confidence. She also identified Sadie as a leader due to her ability to "work with others" and discussed Sadie's success as a "mentor" to other students in the lab. Finally, during Sadie's tenure in the research network, her independent project (for which she earned course credit as an independent study) was strong enough to warrant Dr. Fiona to suggest their pursuing a coauthored manuscript for publication. Dr. Fiona is working with Sadie and a handful of other students on manuscriptssomething more common for Dr. Fiona than other faculty members in the network. Even though Sadie is now in graduate school, Dr. Fiona is "still writing her letters of recommendation and doing all of those academic things" in addition to working with Sadie on "trying to get her paper published."

Summary: Sadie. Sadie's vignette illustrates the positive feedback loop between science-related cultural capital and faculty recognition in building and affirming a student's science identity. From the start, Sadie demonstrates the kind of science-related cultural capital that is easily recognizable to faculty: she enters the network with a foundation of early exposure and family involvement in science; she exhibits strong self-recognition as a "science person," the wherewithal to seek out research experiences, an interest in pursuing a research career in science, and enjoyment of the research process. These factors helped Sadie receive immediate recognition and develop a strong mentorship bond with Dr. Fiona, which led to additional opportunities for her to develop science-related cultural capital through participating in scientific outreach, developing independent research, and collaborating on a publication. With ease, Sadie demonstrated a sophisticated understanding about how to navigate the graduate application process and harness her social capital to collaborate with one of Dr. Fiona's colleagues in her graduate work.

\section{Vignette 2: Recognizing Cultural Capital through Institutional Programs}

Student's Perspective: Sheldon. Sheldon, an African-American student, initially got "excited about science" through an early science project he completed in elementary school with the help of his parents, both of whom work in health science careers (his mother is a nurse and his stepfather is a radiologist technician). He plans to pursue medical school after graduation. 
Sheldon joined the biology research network early in his freshman year through the recommendation of another student who was working in the network and was a part of the institution's Louis Stokes Alliance for Minority Participation in the Sciences (LSAMP). ${ }^{5}$ Sheldon was also one of 12 freshman students admitted into LSAMP, which works with students from underrepresented groups to provide support throughout their collegiate tenure (both in classes and through research opportunities). His colleague in LSAMP suggested Sheldon approach Dr. Fiona to work in the research network. After their meeting, he shortly began to work in the lab.

Sheldon quickly excelled in the lab. He was able to "run his own project" during the summer leading up to his sophomore year (and Dr. Fiona and Sheldon are currently turning his independent research project and results into a manuscript). He also self-identified as a "leader in the lab" and as "very confident" with his research skills. Owing to his scientific competence, Dr. Fiona hired Sheldon to recruit other students by traveling to various science classes on campus and giving minipresentations on the work of the biology research network. He has also pursued an additional research internship overseas. Finally, his view of science changed due to his work-transforming his understanding of the day-to-day practices of science and the impact of the scientific process. When asked about this transformation, he responded,

So if you would have asked me this question before I'd begun doing research, being successful in science is ... like curing cancer or finding - a cure for AIDS ... But really I guess what it means to be successful in science is just not getting discouraged. A lot of science is tedious, a lot of science won't work the first time that you do it. But as long as you ... keep trying it over and over again and ... you're active and you care about what you're doing ... even the small little successes of ... figuring something out, like that's what success is.

Faculty Perspective: Sheldon. Dr. Fiona commented how she "couldn't believe" she let Sheldon join the research network during his freshman year of college. However, due to Sheldon's involvement in LSAMP (from which Dr. Fiona says she regularly recruits for the research network) and Dr. Fiona's positive association with students from this program, she chose to recruit Sheldon as a freshman.

Dr. Fiona mentions how Sheldon emerged as a strong mentor and leader. She identifies Sheldon as a mentor to his peers based on his ability to "take note of what someone else is interested in and share"; he also gives "other people ideas and advice on opportunities." She has also engaged him in recruitment across campus for the research network. As with Sadie, Dr. Fiona is also actively working with Sheldon to "pull together" a manuscript for submission with his ongoing research in the network at the center of this paper.

\footnotetext{
${ }^{5}$ LSAMP assists universities and colleges in diversifying the nation's (STEM) workforce by increasing the number of STEM baccalaureate and graduate degrees awarded to students from underrepresented groups. The LSAMP program takes a comprehensive approach to student development and retention. Particular emphasis is placed on transforming education through innovative, evidence-based recruitment and retention strategies, and relevant educational experiences in support of racial and ethnic groups historically underrepresented in STEM disciplines (NSF, 2017).
}

Summary: Sheldon. Sheldon's vignette illustrates another path to faculty recognition we find in our data: the value of institutional programs like LSAMP. From the start, Sheldon demonstrates many expected forms of science-related cultural capital: he has strong self-recognition as a scientist, which began with his early curiosity about the natural world and positive perception of his parents' careers in health science. Nevertheless, it was his participation in LSAMP that opened the door to Sheldon joining the research network as a freshman. Over his college career, he has expanded his foundation of cultural capital-developing independent research and collaborating with Dr. Fiona in scientific outreach and manuscript preparation. Dr. Fiona recognizes Sheldon as a budding scientist and a leader in her lab, and Sheldon is confident that he is well positioned to pursue his main objective, medical school.

\section{Vignette 3: Building Cultural Capital through Socio-Emotional Mentorship}

Student's Perspective: Sierra. Sierra, a Latina student, describes herself as coming from a "traditional family unit." Although her parents never graduated college and do not have science-related careers, Sierra noted how she thought her grandmother's career as a "radiologist technician" was "really cool." She began to develop her interest in science in 10th grade due to this "really awesome biology teacher" who "made it fun to learn."

After high school, Sierra was chosen to participate in a bridge program, ${ }^{6}$ which allowed her to begin her undergraduate degree at a community college and then transfer to a nearby university to complete her degree. After Sierra completed two biology lecture courses at her community college, Dr. Fatima approached Sierra and invited her to work for the biology research network. Sierra was quickly identified as a leader in the lab, as she regularly provided "mini-instructions" to new students who joined their team. She also discussed her work with Dr. Fatima as "collaborative" in that "she'll [Dr. Fatima] ask me my opinions about stuff ... she'll tell me tasks that I need to accomplish but while I'm accomplishing that, we'll have conversations about what we're doing." Sierra noted how all of the students in the lab "love Dr. Fatima" because "she actually cares about them and ... takes an invested interest in them."

Overall, Sierra feels confident in her abilities as a researcher. She plans to transform her experience in the research network into an opportunity to continue doing research at a 4-year university. Building on the research opportunities she hopes to attain there, Sierra plans to continue with graduate school and earn her $\mathrm{PhD}$ in a "genetics program."

Faculty Perspective: Sierra. Dr. Fatima discussed Sierra's transformation during her work with the research network: "[Sierra] changed from ... a student watching someone, to

\footnotetext{
${ }^{6}$ In general terms, "bridge programs" aim to support students' success in their transition to college. They include summer programs that support freshmen entering college, as well as collaborative programs between 2- and 4-year institutions that target students with strong academic potential to help them achieve their goal of completing their degree at the 4-year institution. Sierra's bridge program is invitation only and includes targeted academic advising, student support services, and a student life component-all of which are designed to help students succeed in meeting academic requirements to transfer from her community college to a partner research university.
} 
being the student mentoring another student, to being an actually paid person off the grant for helping interact and teach and grow." Describing Sierra as her "right-hand person," Dr. Fatima discussed how Sierra completed the work of a graduate student teaching assistant, though only an undergraduate. Dr. Fatima further highlighted how Sierra was skilled at "seeing ... unusual traits" in plants during data collection.

Although Dr. Fatima credits Sierra's transformation and research abilities in the lab, she described Sierra as needing an "extra boost" early in her collegiate tenure. Cognizant of Sierra's participation in the bridge program, Dr. Fatima recognized that Sierra was getting "discouraged" because "she was not just bored but not sure how things [college] was really going for her." In taking Sierra under her wing, Dr. Fatima hoped Sierra's involvement in the research network would provide her with mentorship and research practice so Sierra could attain her graduate study goals. Dr. Fatima noted how she needed to "follow-up" with Sierra more as she was a "first-generation student" and so "had minor things holding her back." Dr. Fatima also mentored Sierra socially by helping her understand appropriate conference attire, practice driving on the interstate, and even try new foods at a conference for the research network. Without this trip, Dr. Fatima suggested Sierra "would never have left the state." Even with her transformation, Dr. Fatima still describes her as "shy" but "she will still reach her goal."

Summary: Sierra. Sierra's vignette illustrates the experience of student who does not come from a science family, but develops high aspirations for herself as a research scientist with the support of a caring mentor. After recognizing that Sierra was a good student and skilled in research in the context of class, Dr. Fatima encouraged Sierra to join her in the research network. While participating in the network, Sierra became a leader in Dr. Fatima's lab. Sierra's participation reinforces her self-recognition and confidence in "bridging" from a community college to the nearby research university. Dr. Fatima clearly values her as a student, as a contributor to the research, and as a leader in the lab, and she has taken additional measures to mentor Sierra both scientifically and socio-emotionally into a solid candidate for a science-related graduate program.

\section{Vignette 4: Struggling to Maintain Faculty Recognition}

Student Perspective: Selena. Selena, a Latina student, has loved plants, animals, and the natural world for as long as she can remember. A first-generation college student, Selena speaks of her experiences growing up in an "immigrant family." Her early passion for nature led her to participate in a summer program at a local community college that places students in research labs at a nearby college and university. ${ }^{7}$ It was through this program that Selena joined Dr. Florence's lab, before the biology research network even got started. This was the first time she actively participated in scientific research. Through her participation in this program, Selena began to recognize herself

\footnotetext{
${ }^{7}$ Like bridge programs, this community college summer program is designed to facilitate and encourage the transfer of community college students to 4-year colleges. Through an intensive 5-week summer program, community college students take STEM courses at partnering 4-year colleges and receive financial support, tutoring, and counseling to encourage student success.
}

as both a scientist and a creative person who is now pursuing a career combining science and art.

Her father actively supports her research, as she regularly "sits with him" and explains her work with plants while also discussing the scientific literature she has read. Neither of her parents had science-related careers or graduated from college, but her father remains committed to understanding his daughter's career-related trajectory.

Early in her time with the network, Selena dropped out of classes after experiencing "problems with her family," while her mother was ill and passed away. Although she was no longer enrolled in school, Dr. Florence allowed Selena to continue her work in the lab. Selena was profoundly grateful for this opportunity, because she "loves" working in the lab and "needs" the compensation.

After nearly a decade of working in Dr. Florence's lab, Selena has developed confidence in her scientific abilities; she described how she is assertive with lab work, in writing papers, lab reports, and even when constructing her own experiments as a student in design school. Selena felt particularly proud of finding a mistake early on in her tenure with the lab that "saved the whole experiment" that semester. Owing to her extended participation in the lab, Selena has seen the research protocols change and, consequently, is tasked by Dr. Florence to "show [new undergraduate students in the lab] how to do seed harvesting or collect seeds." Although she trains others in the lab, Selena does not view herself as an expert, as she "learns something new every day." When training others, Selena also conveys her enthusiasm for working in the research network, as they can all contribute to the "success" of the project.

Now enrolled in design school, Selena has been experimenting with "extracting natural dyeing colors from plants," because "it is something that everybody's concerned about sustainability, organic things."

Faculty Perspective: Selena. Dr. Florence identifies Selena as a "classic immigrant first-generation" college student who needs "a lot of encouragement." Dr. Florence does not mention Selena's efforts in training or mentoring students in her lab over the many years she has performed these tasks in her lab. Nevertheless, other students who have worked in Dr. Florence's lab discussed how Selena helped them learn the protocols and become competent in the day-to-day execution of the research, as well as understand the larger scientific questions driving the biology research network. Although Selena is not among the students Dr. Florence names when we asked about particularly successful students and the leaders in her lab, Dr. Florence has consistently kept her door open to Selena, even when she was not enrolled in school. At this point, however, Dr. Florence feels that Selena should move beyond her lab and explore other opportunities associated with her own degree program.

Summary: Selena. Selena's vignette illustrates the challenges that some students face in maintaining faculty recognition despite a persistent interest in science. Through family and financial challenges, Dr. Florence offered Selena a durable place to pursue and develop her interests, skills, and confidence in science. Selena has not developed independent research in Dr. Florence's lab, and she does not consider herself a leader; nevertheless, she is proud of her contribution to the larger whole. 
Selena's extended time in the lab has supported her development of scientific skills and knowledge, as well as her ability to perform competently in scientific spaces and demonstrate her cultural capital in other contexts. Despite barriers, and minimal recognition from her research advisor, Selena has persisted in research and has begun to exercise her capital by successfully applying to a degree program where she hopes to merge her creative love of nature and scientific background working with plants. Through these efforts, Selena has strengthened her self-recognition and she is finding recognition as a "science person" by faculty at her design school.

\section{Vignette 5: Struggling to Find Self-Recognition Despite Faculty Recognition}

Student Perspective: Simone. Simone identified herself as a first-generation student, a mother, and "older." She also described herself as "not ... the best book-smartest kid in the lab but I've got a hell of a lot of common sense and street smarts," which, in her opinion, "allows her to figure science out." Simone began her tenure in the biology research network after she approached Dr. Frank for an override to attend his genetics class. After "staying for two hours talking about life," Dr. Frank signed her form to attend his genetics course with an offer to become a member of his genetics lab. Simone quickly signed on and began working in the lab. When she began her work in the research network, Simone had difficulty building confidence. She explained, "Whenever you have a job or something that you really enjoy, the bigger fear is having it taken away ... So when I first started I was terrified of messing something up ... that fear was kind of with me for the first couple months." Over time, Simone's confidence grew, and she became proud of her contribution to the research. She discussed her involvement with the protocols associated with the biology research network and how she was able to innovate a new genotyping protocol:

When I started here, the [DNA] isolation process was almost quite literally backbreaking. You would put the plant tissue in a micro centrifuge tube and you add a DNA buffer and then you literally sit there and ground the plant ... It's like doing a set of 30 would take you roughly an hour to 2 hours ... I would go home and my back would hurt and my shoulders would hurt. And my hands, oh my god, my hands would hurt. And so, I was like, "There has to be a different way. This cannot be the only way that we can isolate plants. This is ridiculous!" It's time-consuming; your output is low. I'm only but one person. So he [Dr. Frank] was like, "Well find a different way..." and then I did. And then it worked. So that's what we've been playing with a lot now. It's like a new high-output isolation method. And it grows from like 30 plants in a day into 96 plants within an hour.

Simone also discussed how doing research expanded her knowledge of available job opportunities in science: "Honestly, I think what I didn't realize coming into this that was kind of eye-opening was the fact, 'How many awesome job opportunities are out there?' Working in a lab, even if it's just as a lab technician, I didn't realize that Lab Manager was a thing and could be a thing."

Although Simone expanded her understanding of scientific opportunities and substantially transformed the protocols for the research network, she still did not identify herself as a scien- tist. She even describes rebuffing her 12-year-old, who thinks of her as scientist: "No, I'm not [a scientist]. Stop this nonsense!" When we asked whether she planned to continue her work with the network during her interview in 2015, Simone stated, "Oh, yeah. I told [Dr. Frank] I'm not leaving until I graduate. And even then, I might want to stay."

Faculty Perspective: Simone. When recruiting students for the biology research network, Dr. Frank assesses undergraduate independence as the key characteristic he looks for. With this approach, Dr. Frank has found he likes to recruit "nontraditional older students"-especially "single moms"-as they "have this ability to do just about anything, just to juggle so many things."

Dr. Frank identified Simone as one of those single moms he wanted to have work in his lab, describing her as a "35-yearold," "first-generation, nontraditional," "single mother of two." Dr. Frank relayed how Simone "needed a lot of time," partly because she was "math phobic," and so he spent a lot of time with her "going over calculations." He also suggested that Simone "needed a place where she was loved, so that was mostly what she needed ... is a place where she could hang out and people would treat her with respect."

Yet Dr. Frank also emphasized that during her time working in the network, Simone greatly enhanced the efficiency of the research. Dr. Frank highlighted her achievement:

So much of what we're doing is shoveling coal, and not devising new experiments or anything like that ... what there has been, though, is improving efficiency ... [Simone] really changed that dramatically. Quantum change ... I used to have to have three students at the bench [genotyping work area] to get stuff done, but she made it so one student could do it.

In fact, Dr. Frank recognized Simone's contribution to the research network and sent her to visit a colleague in the network to train other students in her technique.

Through Simone's experience in the lab, Dr. Frank and Simone became friends and even after "she dropped out," they still go to lunch together to catch up and so Dr. Frank can "see her new baby." Even though Dr. Frank remains in touch with Simone, he ultimately thinks he failed with her; "I couldn't get her out of college. But at least I kept her in college a little bit longer, so there's that."

Summary: Simone. Simone's vignette illustrates a different kind of misalignment: despite Simone developing an innovative approach toward genotyping for the research network-which prompted positive scientific recognition from Dr. Frank-she is still unable to fully recognize herself as a scientist. Although Simone demonstrates a growing awareness about the range of potential careers in science, and her contributions ripple throughout the research network, she is unable to close the loop on self-recognition. Her case exemplifies the importance of self-recognition (not merely the recognition by others) and how the development of science-related cultural capital extends beyond the development of technical skills and knowledge. Like Dr. Florence for Selena, Dr. Frank provided a safe space for Simone to practice scientific research and to learn "scientific culture"emphasizing encouragement, flexibility, and extra support for 


\begin{tabular}{|l|l|l|l|l|l|}
\hline Domain of Cultural Capital & Sadie & Sheldon & Sierra & Selena & Simone \\
\hline Interest in Science & & & & & \\
\hline Education \& Career Aspirations & & & & \\
\hline Family Science Exposure & & & & & \\
\hline Research Access & & & & \\
\hline Practicing Science & & & & \\
\hline Scientific Ownership & & & & \\
\hline Leadership in the Lab & & & & \\
\hline Scientific Collaboration & & & & \\
\hline Performing Science & & & \\
\hline Using Social Capital & & & \\
\hline Embeddedness in Lab \& Field & & & & \\
\hline
\end{tabular}

\begin{tabular}{|l|l} 
High Capital \\
Medium Capital \\
Low Capital
\end{tabular}

FIGURE 1. Eleven domains of science-related cultural capital that influence faculty recognition. Although we conceptualize each domain as a continuum representing students' lower to higher access to and development of cultural capital in that particular domain, here we provide a rough categorization (dark = high; light = low) of students highlighted in the vignettes for each domain.

Simone. Even with the recognition afforded to Simone, she ultimately left school before finishing her undergraduate degree; nevertheless, due to her research experience, she may continue to be viewed as a "science person" in her personal network.

\section{Disaggregating Cultural Capital}

We use the vignettes to shed light on what cultural capital looks like in the context of undergraduate research. Overall, the characteristics of these and other students in the biology research network, coupled with the faculty data, led to our identification of 11 domains of cultural resources that repeatedly emerged in our research. We conceptualize each domain as a continuum representing students' lower to higher access to and development of cultural capital in that particular domain. We divide these domains into three categories: 1) domains representing students' initial access to cultural capital in science that lays the foundation for students' participation in the research network (interest in science, education and career aspirations, family attitudes and exposure to science, and their access to the research network); 2) domains representing students' development and practice of cultural capital in the context of research (attitude toward scientific practice, scientific ownership, leadership, and collaboration); and 3) domains that reflect students' abilities to use their cultural capital in science beyond the boundaries of the network (performance of science, use of social ties to access novel opportunities, and their embeddedness in the lab and broader field).

Individually, the domains we identified in our data are not new to scholarship on science education-but viewing them through the lens of cultural capital allows us to disaggregate the set of cultural resources students draw on, develop, and deploy in the context of research, and how their accumulation of cultural capital renders them more or less visible to faculty. As Figure 1 illustrates, Sadie demonstrates high capital in each domain, and Sheldon demonstrates high capital overall; these students are recognized and provided opportunities that allow them to further develop their capital in the field. In contrast, Sierra, Selena, and Simone demonstrate more variable cultural capital in science, resulting in more variable recognition and fewer opportunities to build capital overall.

\section{Faculty Recognition of Students: The Alignment (or Misalignment) of Cultural Capital}

Broadly, our data suggest that faculty recognition has to do with an alignment (or misalignment) between students' science-related cultural capital and faculty expectations. When faculty see students demonstrate the attitudes and dispositions in which they have been enculturated in the sciences, students are rendered recognizable. As our vignettes demonstrate, most students in this research network, including those from underrepresented groups in science, demonstrate a strongto-budding self-recognition as a scientist or "science person"; however, the degree to which they were recognized by faculty was far more variable. Importantly, we do not reinforce a deficit model toward students. Although we do not blame faculty for the inclination (and structural pressure) to prefer students who immediately demonstrate high cultural capital in science, we argue that faculty can encourage the success of students with less initial scientific cultural capital by broadening their scopes of recognition to affirm these students' identities and interests even if they do not fit the typical pattern.

To understand the variation in faculty recognition, we examined our data set for patterns that could provide insight into the forms of cultural capital that particularly impacted students' recognition. Several prominent themes emerged: 1) students interested in pursuing research science careers were more readily recognized than those interested in health science and nonscience careers; 2) students who participated in institutional programs to support students underrepresented in science received recognition for their participation in these programs; 3) students with competing family responsibilities struggled to maintain faculty recognition; and 4) faculty who expand their scopes of recognition can help students develop cultural capital in science. We discuss each in turn.

Students Interested in Pursuing Research Science Careers Were More Readily Recognized Than Those Interested in Medical/Health Science and Nonscience Careers-Especially among Faculty Who Emphasized Research in Their Own Science Identities. Carlone and Johnson's (2007) seminal work found that women of color in research science fields had received recognition from "established members of the scientific community" (p. 1199), whereas those in health 
science careers had to redefine their self-recognition and find recognition from other groups of meaningful others who shared their altruistic values.

Our data suggest that it might also work in reverse: students with the cultural capital to aspire to research careers garner faculty recognition more easily. Of course, we also see evidence that exposure to research also opens up science as something "thinkable" (Archer et al., 2012, 2014; Gazley et al., 2014).

Our findings indicate that it was the rule and not the exception for undergraduate students (including those from underrepresented groups) to gain positive recognition from faculty when students expressed an interest in pursuing research science trajectories. Simply put, this "disposition" toward a research science trajectory was easily recognized by faculty. Take the example of Sadie in vignette 1, who knew from an early age she would pursue a science-related career, who outwardly expressed her aspirations to her faculty mentor, and who strategically worked toward her goal of attending graduate school in a science-related field.

Faculty easily recognize students like Sadie because of her curiosity around scientific discovery; her engagement in the scientific process; and her genuine "enjoyment" of the tediousness of lab work, data collection, and analysis. Sadie's characteristics demonstrate strong cultural capital in science: she has been exposed to the notion of science research and enculturated to find the incremental development of scientific knowledge both interesting and desirable. Although we view entering research with this perspective as a marker of cultural capital in science, we also find that students can develop this disposition, and thus build cultural capital, through research. Several students described how research participation itself helped them develop an appreciation for the incremental development of scientific knowledge (in contrast to the popular notion of "Eureka!" moments of scientific discovery). Certainly, students still hoped for high-impact discoveries, but as they developed their scientific dispositions, they recognized that even these require tedious periods of data collection, analysis, and rethinking in response to peer review. Both Sheldon and Sierra also demonstrated cultural capital development through their understanding and appreciation for the incremental development of scientific knowledge and how their work contributed to larger scientific goals of the project. We view this as an important demonstration of the way research participation itself can help students build scientific cultural capital.

Overwhelmingly, faculty discussed their particular engagement with students with whom they could "connect" about scientific topics in class and lab. One faculty member playfully labeled these individuals (including himself) as "bio-nerds," saying, "Maybe just their being more bio-nerds made it easy for me to bio-nerd out with them." Of importance, those students who showed interest in pursuing STEM and in "bio-nerding" with faculty were more likely to be described by both male and female faculty as "strong leaders" in the research network and were also students who developed the "strongest relationships" with faculty. Another faculty member put it this way: "I do think I tend to have closer relationships to the students who end up going to graduate school. We share more common interests much of the time." And yet another indicated how she develops strong bonds with students when they share scientific interests:
I think these were the students that I had the most fun science conversations with. That's probably the real key with all these people [students identified as leaders in the network], I can think back to just talking about biology ... so I feel like we made real connections talking science.

However, several students, particularly those from underrepresented groups, discussed their desire to pursue a career in a nonscience or health-related field (e.g., medical doctor) while participating in the biology research network, including Sheldon, who is featured in our vignettes. The sentiment of fostering those interested in PhD-level scientific careers over those students who eagerly pursued nonscience and health science careers was apparent in our work. This was especially true among faculty with a strong research-based science identity, in contrast to those who emphasized their roles as teachers. For example, one faculty member discussed her interest in fostering students who would likewise go into life sciences research, rather than medical sciences:

I'm an evolutionary ecologist and so I'm interested in attracting students who are already interested in ecology and evolutionary biology and genetics. So if a student is very clearly medical sciences driven and two students were otherwise equal, then, it's not a red flag, but to me it's that I'm more interested in training the students who are interested in the field, as opposed to just using it as a stepping-stone to do something completely different.

This faculty member's preference to foster students with long-term life science research interests, who appear to be following in her academic footsteps, is the epitome of what Bourdieu describes as cultural capital: the shared tastes, preferences, and attitudes that make it feel "natural" for faculty to connect with certain students over others. Nevertheless, depending on a "natural" connection has consequences-in the form of opportunity and practice-that disproportionately exclude students who do not share this scientific disposition. Although research-oriented faculty in this network did not dismiss students pursuing nonscience and health-related careers entirely, the pursuit of research by these students was largely viewed as an effort to "check a box" needed to get into medical school ${ }^{8}$ or to get a line on a resume, rather than a serious interest in contributing to the development of scientific knowledge.

Criticizing faculty for having "natural connections" with students based on mutual interests is unproductive. Nevertheless, it is vital to help faculty become aware of their potential for implicit bias and the limitations of considering research science to be the ideal science trajectory. Brickhouse and colleagues (2000) argue that the research science community is "too distant and irrelevant" to most students' prior experience with science in the real world (e.g., in the health sciences or in agriculture) (p. 444), and, relatedly, that research science is an "excessively narrow view of what it means to engage in science" (p. 445).

${ }^{8}$ Unlike the obscure nature of the cultural capital that students need to be successful as research scientists, there have been more explicit efforts to enumerate and disseminate the expectations around cultural capital that students need to successfully gain admission to medical school (e.g., AAFP, n.d.; Seymour et al., 2004). 
In contrast, understanding why students may pursue a health science or nonscience career may help faculty develop greater appreciation for the value of these alternative scientific trajectories (i.e., applied science and science in everyday life). In particular, students from underrepresented groups may seek health science and other professional careers because they offer significant_and more immediate-opportunities for social and economic mobility and for making positive contributions to their home communities and society at large (Carlone and Johnson, 2007; Hurtado et al., 2009b).

Our results further indicate that faculty should not assume that undergraduates are even aware that research science careers are "a thing" (as Simone in vignette 5 put it when she realized that she could potentially pursue a career as a lab manager). Far before college, many students-and especially those from underrepresented groups-may not view scientific futures as "thinkable" (Archer et al., 2014). Owing to gaps in representation, many students from underrepresented groups lack access to role models in research science careers, but like Sheldon in vignette 2 , they are more likely to have family members and other role models working in the health sciences and other professional, nonscience careers (Hurtado et al., 2009b). Thus, many students in this study were aware of a wide range of viable and desirable health science and nonscience careers, but they demonstrated less familiarity with the ways that their undergraduate research experience could translate into a research career path. Nevertheless, our work demonstrates that students-like Simone-can develop an interest in and awareness of the potential of scientific futures through exposure, encouragement, and practice.

Students Who Participated in Institutional Programs to Support Underrepresented Groups in the Sciences Received Recognition for Their Participation in These Programs. In this study, several students from underrepresented groups participated in a structured institutional program designed to aid their undergraduate tenure. Studies have found that students who participate in "bridge programs" or similar institutional programs have a higher likelihood of graduation (Murphy et al., 2010) and report increased social support, a better understanding of scientific research, and motivation for graduate studies in STEM (Gasiewski et al., 2010; Ashley et al., 2017). These programs may be particularly important for women and underrepresented students pursuing degrees in life sciences and STEM, as these students attend 2-year community colleges at higher rates (Mooney and Foley, 2011; Starobin et al., 2013).

Our data indicate that participation in institutional programs, like LSAMP or bridge programs, helped students gain recognition for their science identities_-and even initial access to the research network-from their faculty mentors. At the most basic level, it is not clear that students like Selena, Sheldon, and Sierra would have had access to the research network had they not participated in these programs. Selena's participation her community college's bridge program led to her opportunity to do research in Dr. Florence's lab. Sheldon's engagement in LSAMP fostered access to Dr. Fiona's lab through another LSAMP student already working in the research network and affirmed his research potential for Dr. Fiona. Sierra may have still been recognized without her institution's bridge program, but Dr. Fatima has been deeply committed to helping her successfully transition to the neighboring research university.

We posit that the reasons why students received recognition for their participation in institutional programs are threefold. First, these programs provide students with practical resources, mentorship, and a peer network that will help them succeed in classes and in college (Ovink and Veazey, 2011). Second, these programs make explicit (and teach) the kinds of academic and scientific cultural capital that will help students succeed. Through hands-on mentorship, required research experiences, and in some cases supplementary courses, these programs expose students to the range of careers in science, as well as the oft-unspoken cultural expectations of the field. Encouraging or even requiring undergraduate research experiences offers students "safe spaces" to practice both their scientific skills and dispositions-a technique found to be particularly effective for students from underrepresented groups (Ovink and Veazey, 2011; Gazley et al., 2014). These programs also help with socializing students into the academic community more broadly, making familiar the cultural practices of the institutions themselves (i.e., transfer policies, graduate school opportunities, etc.).

Finally, our data make plain that these programs also serve as perceptual filters for faculty: they communicate to faculty students' interest in science as well as the institution's selection of them as students with strong potential. This enables faculty to view these students as potentially low risk and high reward and worth the potential investment of extra time and resources. Institutional programs, then, strengthen the science identity and cultural capital feedback loop: they affirm students' self-recognition, provide a strong context for their development of science-related cultural capital, and serve as a cognitive shortcut for faculty recognition, which then opens doors to enhanced opportunities for students to practice and develop cultural capital in the context of research.

\section{Students with Competing Family Responsibilities Struggled} to Maintain Faculty Recognition. Several students in this study struggled to maintain faculty recognition and to persist in science because of competing family obligations. Selena and Simone exemplify this situation: Selena took time away from school to take care of her ill mother and Simone juggled the responsibilities of a single-parent household and the birth of an additional child during her junior year-ultimately leaving college before graduating.

Although we did not explicitly ask all students whether they experienced competing family obligations, the students for whom this theme featured prominently in their interviews were from underrepresented groups, with most also identifying as women. The literature confirms that competing family responsibilities during college are inequitably experienced by women and by students from underrepresented groups (Ceci and Williams, 2010, 2011; Allen et al., 2016), who may have fewer financial and social resources from which to draw in times of need.

To our knowledge there has been little work examining undergraduates' experiences with family and parenting responsibilities, particularly in the sciences. Women studying engineering anticipate that family responsibilities will pose a barrier to their career success (Hawks and Spade, 1998), and although both men and women value scientific careers, 
women value family, and particularly parenting responsibilities, more highly than men (White and Massiha, 2016). More broadly, there is evidence that women leave professional careers due to the difficulties of reconciling competing demands of work and family (Stone, 2007). Academic women also report challenges (as well as some benefits) of integrating the multiple roles and competing demands of their work and family lives (Ward and Wolf-Wendel, 2004). Further, Griffin et al. (2015) found that women in science experience "penalties" for having "investments outside the lab" (e.g., teaching, extracurricular interests, and family-rearing) and were perceived by others as less serious.

Latinas, in particular, may experience the "double-edged sword" of the cultural value of familismo: although close-knit family ties provide strong emotional and social support for students' success in college, the expectation that they put the needs of the family ahead of their individual needs can also pull students away from their studies (Sy and Romero, 2008). As an alternative form of cultural capital, familismo may serve a student well overall, but in the context of higher education, it may be perceived by faculty as a lack of commitment to science and research. Sy and Romero (2008) also find that Latina college students consider their financial and caretaking responsibilities to family as voluntary, not obligatory. This is consistent with the way Selena frames her time away from school, caring for her father after her mother passed away.

Just as students do not voice resentment toward their family responsibilities, faculty in this network do not speak disparagingly of students' competing family responsibilities. This may certainly reflect a social desirability bias on the part of faculty. Nevertheless, family obligations may signal something less than a single-minded commitment to science on the part of students, contributing to a mismatch between students' science identities, their scientific dispositions, and the expectations that garner recognition by faculty (Griffin et al., 2015). In the end, students' commitment to family responsibilities may contribute to inconsistent recognition from faculty, which may to lead to fewer opportunities to develop science-related cultural capital and, ultimately, to a disrupted science identity based in gendered and ethnic "failures of recognition" (Carlone and Johnson, 2007, p. 1204). This is an area ripe for further research.

Nevertheless, when faculty shifted their expectations to accommodate students' family responsibilities, students in this study demonstrated their commitment to science and made important contributions to the research network. Specifically, both Dr. Frank and Dr. Florence offered their labs as a kind of "home base" for Simone and Selena as they juggled their family responsibilities, understanding that the time these students could commit to research might ebb and flow over time, yet fostering their labs as a "safe space to practice" their science identities and build cultural capital (Ovink and Veazey, 2011, p. 386). This flexibility from faculty ultimately enabled Simone to innovate and improve a key lab protocol and Selena to hone her science identity and disposition so that she could translate it to another field. Even if these students do not attain degrees in the life sciences or STEM, their scientific stories, and the stories they foster in others, may not be over.
Faculty Who Expand Their Scope of Recognition Can Help Students Develop Cultural Capital In Science. In the above three themes, we discuss the ways that faculty more easily recognize students who "fit" with their expectations by demonstrating scientific cultural capital that is familiar and expected. Viewed through a lens of cultural capital, the preference of faculty for students "like me" is unsurprising, yet it does have consequences: opening more doors for students who fit the mold and potentially excluding those students who do not. Yet, in our data, we find that faculty who broaden their scopes of recognition can support students with nascent and budding self-recognition, if not the expected disposition, to also develop scientific cultural capital.

Dr. Fatima serves as an exemplar for how to deliver the "extra boost" some students may need: she provided academic mentorship to Sierra-helping her develop research skills and scientific knowledge-but Dr. Fatima also recognized that Sierra needed more extensive professional and socio-emotional mentorship and stepped in to support her as she developed not only the technical knowledge and skill, but also the cultural "know-how" that she needed to fit in a professional context. Similarly, Dr. Frank recognizes and values the alternative forms of capital Simone brings to her work-as a "single mom" who can "do it all." Yet he lends Simone extra support-especially in developing her confidence with mathematical calculations and in accommodating her family responsibilities. Over time, Simone flourishes and creates a protocol innovation that vastly improves the efficiency of the research project.

Examples of faculty expanding their scope of recognition and helping students develop cultural capital in science abound in this network. Together, they demonstrate that, when faculty look beyond students' initial dispositions and beyond their own expectations for cultural capital, they can affirm students' potential as budding scientists. In particular, we find that, when faculty singled out students for individual opportunities (whether personally inviting them to participate in research, pursue independent projects or other internships, collaborate on papers or presentations, or participate in scientific outreach), students viewed this as a particularly affirming kind of recognition. In addition to being an important form of mentorship, these opportunities created contexts for students to develop their scientific cultural capital and display their science identities for nonscience others, peers, or the science community more broadly.

This theme also reveals the importance of faculty recognizing the need to explicitly teach students the "rules of the game"-from the value of seeking out research internships (Pender et al., 2010; Binder et al., 2015) and social networking within the field (Stanton-Salazar, 2010), to knowing how to dress for a professional meeting. Of course, these are not the only rules of the game, but they are examples of the kind of scientific dispositions that faculty may take for granted. The value of these more subtle manifestations of cultural capital is often overlooked in comparison with disciplinary knowledge or laboratory skill; yet without this capital, students may find themselves inadvertently misrecognized as "outsiders" in the field. This can undermine students' science identities and ultimately drive them away from science. Thus, understanding that many students may not be enculturated in the cultural capital of science and academia and making the effort to explicitly 
teach the norms, values, and dispositions are important ways that faculty can help to broaden science participation.

\section{Limitations}

This study has several limitations. Most notably, our study was limited to examining faculty-student relationships within one research network. It is possible that there are unique features of this network influencing the characteristics of faculty-student relationships and their interactions. However, we argue that this is not a critical flaw in the study. In fact, because we were able to examine faculty-student relationships within this network and across a wide range of institutions, we argue that our findings have strong credibility and perhaps greater generalizability beyond this particular case. Certainly, faculty-student research relationships have a high degree of variability based on the individuals involved, the institutional context, and the kind of research being done. As such, studying faculty-student research relationships within one research network constrained (at least to some degree) differences in students' actual research practice. This allowed us to focus our analysis on identifying patterns in the cultural capital that render undergraduates recognizable to faculty in the context of undergraduate biology research. Future work should examine how institutional factors and different types of research (including course-based research) influence cultural capital and how faculty recognition occurs.

In addition, participants in our study may not be representative of either undergraduate researchers or faculty mentors beyond this research network. In particular, it is unusual that this research network expressly articulates the training, mentorship, and participation of large number of undergraduates as a central objective of the research project. As a result, our faculty may be especially attuned to their roles as mentors to undergraduate researchers. Further, because this project largely includes faculty from primarily undergraduate institutions, 2-year schools, and other institutions with high teaching loads and fewer research requirements for faculty, many of the faculty involved in this project are operating outside their institutional norms both by working on a large, multisited research project and by mentoring undergraduates in research. Students from these institutions are also unlikely to have wide access to research opportunities, so they, too, are operating outside of their institutional norms. We speculate that this may lead to heightened faculty attentiveness to their role as mentors and to students actively seeking research opportunities; yet we also speculate that both faculty and students may have less institutional support for this type of work. Nevertheless, the role of institution type in supporting faculty recognition and students' development of scientific cultural capital, along with potential pathways for student success in different institutional contexts, is yet unexplored. This is an important area for future research.

Another limitation is that our data underrepresent the experiences of students who did not receive strong faculty recognition. With few exceptions, students in our study overwhelmingly reported positive experiences with research and faculty mentorship. Although we can identify students who received less faculty recognition from our interviews with faculty, these students were underrepresented in our student interviews. Many of these students had already left the research network at the time of our interviews, but this raises the question of whether there may be a "dose effect" or confirmation bias related to research recognition from faculty: students who leave the lab after a short time may be underrecognized (in retrospect), whereas (some) students who persist may earn recognition over time. Selena's case, however, suggests that it is not that simple. Future research should examine students' self-recognition, faculty recognition, and the development of cultural capital in real time to better understand the experiences of students who go mis- or underrecognized by faculty.

Relatedly, the interviews with students and faculty may have been influenced by a social desirability bias that made interviewees reluctant to report negative experiences with research and mentorship. In both cases, the structure of the interviews explicitly encouraged both students and faculty to be candid about their experiences. We further aimed to reduce this risk with students by having an undergraduate conduct most of the interviews, thus reducing the status gap between participants and researchers. In addition, our longitudinal engagement with the project allowed us to build trust with both students and faculty over time-creating a space for them to speak candidly about their experiences with research and recognition.

Finally, although we identify a set of cultural resources that faculty recognize among students in this research network, we do not argue that these are the only domains of cultural capital that matter, nor do we argue that faculty recognition is the only factor facilitating students' development of cultural capital in the sciences. Rather, in drawing on context-rich qualitative data to examine human experience in context, we find that cultural capital plays an undertheorized and underoperationalized role in whether and how students in this distributed research network are recognized by faculty and that faculty recognition in turn facilitates these students' opportunities to develop capital in science. We encourage further research to determine the broader, analytic generalizability of our findings, to identify other domains of cultural capital that may influence faculty recognition of students in other contexts, and to identify which domains most strongly impact faculty recognition.

\section{CONCLUSION}

In this paper, we disaggregated what cultural capital looks like in the context of undergraduate biology research-with an emphasis on the experiences of students from underrepresented groups and first-generation college students. Building upon the seminal work of Carlone and Johnson (2007), we examined how differences in students' cultural capital impact their recognition from faculty. Through an analysis of interviews with students and their faculty research mentors, we identified a set of intersecting cultural resources that help to render students recognizable to faculty. Broadly, we argue that faculty recognition often reflects an alignment (or misalignment) between the cultural capital that students possess and perform and what faculty expect to see. We investigated why mis- or underrecognition occurs, and how this influenced students' opportunities to further develop cultural capital.

Through context-rich vignettes, we illustrate how students who initially demonstrated the expected and familiar scientific dispositions were easily recognized and affirmed by their faculty mentors. These students were given opportunities to practice and develop capital (encouraged to do independent research projects, to collaborate on presentations, posters, publications, 
etc.) and, ultimately, they were able to execute their cultural capital to gain access to further opportunities like other research internships or graduate school. In contrast, those who did not demonstrate the expected forms of cultural capital had a more difficult path to attain recognition from faculty (and sometimes self-recognition). As our vignettes illustrate, some of these students left science; in other cases, they persisted, but were generally not encouraged to develop independent research projects or develop other forms of cultural capital through collaborations with faculty.

To enhance our understanding of why some students were mis- or underrecognized, and how this influenced students' development of scientific cultural capital, we explored our data set for patterns of explanation. By triangulating interview data with undergraduates and faculty participating in a multi-institutional biology research network, we identified four key themes that crosscut students' experiences and appear to influence students' recognition and affirmation by faculty and subsequent development of scientific cultural capital. First, faculty more easily recognized students interested in research science trajectories over students interested in health science and nonscience careers. Faculty perceived these students as more genuinely interested in research and found them more relatable due to shared interests. Second, faculty more easily recognized students who participated in institutional programs to support students from groups underrepresented in STEM. In addition to serving as an important resource for support and mentorship, we posit that these programs served as perceptual filters that helped faculty identify students who were committed and likely to succeed in science. Third, students juggling competing responsibilities to family-disproportionately women and students from underrepresented groups-found it more difficult to maintain faculty recognition. Although faculty were largely sympathetic to these students' competing responsibilities, the students nevertheless struggled to persist in research and in science trajectories. Finally, we found that faculty who broadened their scope of recognition to affirm the science identities of students with fewer incoming cultural resources in science supported their development of scientific cultural capital and their success in the field.

Together, these results underscore the powerful role that cultural capital plays in attaining faculty recognition, which reinforces students' self-recognition and catalyzes opportunities for students to further develop capital through practice. Although cultural capital often operates to reinforce and naturalize the status quo, we do not emphasize the importance of cultural capital to reify deficit thinking about the competence or potential of students from groups underrepresented in science. Rather, we view this analysis as bringing important insight to the role and responsibility of institutions and faculty to broaden their recognition of students who do not initially demonstrate the expected forms of cultural capital. Our analysis indicates that this pays off: students can and do develop scientific cultural capital through practice, but this requires access to research and to academic and socio-emotional mentorship that explicitly teaches students the "rules of the game." Fundamentally, this requires faculty to recognize and affirm students' interest and budding self-recognition, even if it does not reflect their personal experiences or their initial expectations for students on a scientific career path.
Our data suggest several "low-risk" steps that faculty can take to expand recognition and support for students who enter the field with fewer cultural resources in science. We do not argue that these are the only possible recommendations, nor that they guarantee success or persistence among students. Future research should expand on these suggestions and examine which strategies are particularly high impact. Our suggestions include

- Understanding that students may not be privy to tacit knowledge associated with scientific settings and, thus, explicitly teaching students the "rules of the game" in science.

- Introducing students to the idea of scientific research trajectories, while affirming the aspirations of students on health science and nonscience career trajectories.

- Singling students out for individual professional development opportunities (e.g., outreach, independent research, posters, presentations).

- Recognizing that students possess alternative forms of capital that are potential resources for success.

- Recognizing that some students (especially women and students from underrepresented groups) will have competing family obligations, and accommodating these responsibilities through flexible scheduling and maintaining the lab as a "home base."

- Recognizing that some students (particularly those from underrepresented groups) may need academic and socio-emotional mentorship as part of their professional development.

\section{ACKNOWLEDGMENTS}

Support for this research was provided by a grant from the NSF (award no. 1354771). Its contents are solely the responsibility of the authors and do not necessarily represent the official views of the NSF. We especially thank the members of the biology research network (faculty and students) at the heart of this study. We appreciate the Biology Education Research Group at the University of Georgia for their thoughtful feedback, in particular Tessa Andrews and Julie Dangremond Stanton. We thank Erin Dolan, Evan Conaway, Zoheb Sulaiman, and Jack Cherry for their contributions over the course of the project and insights toward our interpretation of data. Finally, we thank two anonymous reviewers for valuable questions and critique that greatly improved this paper.

\section{REFERENCES}

AAFP. (n.d.). Getting into medical school. Retrieved November 8, 2018, from www.aafp.org/medical-school-residency/premed/getting-into-med -school.html

Adamuti-Trache, M., \& Andres, L. (2008). Embarking on and persisting in scientific fields of study: Cultural capital, gender, and curriculum along the science pipeline. International Journal of Science Education, 30(12), 1557-1584

Aikenhead, G. (1995). Border crossing into the subculture of science. Studies in Science Education, 27, 1-52.

Allen, J., Muragishi, G., Smith, J., Thoman, D., \& Brown, E. (2016). To grab and to hold: Cultivating communal goals to overcome cultural and structural barriers in first generation college students' science interest. Translational Issues in Psychological Science, 1(4), 331-341.

Archer, L., Dawson, E., DeWitt, J., Seakins, A., \& Wong, B. (2015). "Science capital": A conceptual, methodological, and empirical argument for 
extending Bourdieusian notions of capital beyond the arts. Journal of Research in Science Teaching, 52(7), 922-948.

Archer, L., DeWitt, J., Osborne, J., Dillon, J., Willis, B., \& Wong, B. (2010). "Doing" science versus "being" a scientist: Examining 10/11-year-old schoolchildren's constructions of science through the lens of identity. Science Education, 94, 617-639.

Archer, L., DeWitt, J., Osborne, J., Dillon, J., Willis, B., \& Wong, B. (2012) Science aspirations, capital, and family habitus: How families shape children's engagement and identification with science. American Educational Research Journal, 49(5), 881-908.

Archer, L., DeWitt, J., \& Willis, B. (2014). Adolescent boys' science aspirations: Masculinity, capital, and power. Journal of Research in Science Teaching. 51(1), 1-30.

Ashley, M., Cooper, K.M., Cala, J.M., Brownell, S.E., \& Shuster, M. (2017). Building better bridges into STEM: A synthesis of 25 years of literature on STEM summer bridge programs. CBE-Life Sciences Education, 16(4), es3.

Binder, J., Baguley, T., Crook, C., \& Miller, F. (2015). The academic value of internships: Benefits across disciplines and student backgrounds. Contemporary Educational Psychology, 41, 73-82.

Bourdieu, P. (1997). The forms of capital. In Halsey, A. H., Lauder, H., Brown, P., \& Wells, A. S. (Eds.), Education: Culture, economy and society (pp. 46-58). Oxford, UK: Oxford University Press.

Bourdieu, P. (2004). Science of science and reflexivity. Chicago: University of Chicago Press.

Bourdieu, P., \& Passeron, J. (1990). Reproduction in education, society and culture. London: Sage.

Bourdieu, P., \& Wacquant, L. (1992). An invitation to reflexive sociology. Chicago: University of Chicago Press.

Brickhouse, N. (2001). Embodying science: A feminist perspective on learning. Journal of Research in Science Teaching, 38(3), 282-295.

Brickhouse, N., Lowery, P., \& Schultz, K. (2000). What kind of a girl does science? The construction of school science identities. Journal of Research in Science Teaching, 37, 441-458.

Calabrese Barton, A., Kang, H., Tan, E., O'Neill, T., Bautista-Guerra, J., \& Brecklin, C. (2013). Creating a future in science: Tracing middle school girls' identity work over time and space. American Educational Research Journal, 50, 37-75.

Carlone, H., Haun-Frank, J., \& Webb, A. (2011). Assessing equity beyond knowledge- and skills-based outcomes: A comparative ethnography of two fourth-grade reform-based science classrooms. Journal of Research in Science Teaching, 48(5), 459-485.

Carlone, H., \& Johnson, A. (2007). Understanding the science experiences of successful women of color: Science identity as an analytic lens. Journal of Research in Science Teaching, 44(8), 1187-1218.

Carlone, H., Scott, C., \& Lowder, C. (2014). Becoming (less) scientific: A longitudinal study of students' identity work from elementary to middle school science. Journal of Research in Science Teaching, 51(7), 836869.

Carter, P. L. (2003). "Black" cultural capital, status positioning, and schooling conflicts for low-income African American youth. Social Problems, 50(1), 136-155.

Ceci, S., \& Williams, W. (2010). Gender differences in math-intensive fields. Current Directions in Psychological Science, 19, 275-279.

Ceci, S., \& Williams, W. (2011). Understanding current causes of women's underrepresentation in science. Proceedings of the National Academy of Sciences USA, 108, 3157-3162.

Chang, M., Eagan, M., Lin, M., \& Hurtado, S. (2011). Considering the impact of racial stigmas and science identity: Persistence among biomedical and behavioral science aspirants. Journal of Higher Education, 82(5), 564-596.

Charmaz, K. (2006). Constructing grounded theory. Los Angeles: Sage.

Chemers, M., Zurbriggen, E., Syed, M., Goza, B., \& Bearman, S. (2011). The role of efficacy and identity in science career commitment among underrepresented minority students. Journal of Social Issues, 67, 469-491.

Claussen, S., \& Osborne, J. (2013). Bourdieu's notion of cultural capital and its implications for the science curriculum. Science Education, 97, 58-79.

DeGraaf, N., DeGraaf, P., \& Kraaykamp, G. (2000). Parental cultural capital and educational attainment in the Netherlands: A refinement of the cultural capital perspective. Sociology of Education, 73(2), 92-111.
DiMaggio, P. (1982). Cultural capital and school success: The impact of status culture participation on the grades of US high school students. American Sociological Review, 47(2), 189-201.

Donmoyer, R. (2000). Generalizability and the single-case study. In Gomm, R., Hammersley, M., \& Foster, J. (Eds.), Case study method (pp. 45-68). London: Sage.

Dumais, S. (2002). Cultural capital, gender, and school success: The role of habitus. Sociology of Education, 75(1), 44-68.

Dumais, S. (2006). Early childhood cultural capital, parental habitus, and teachers' perceptions. Poetics, 34(2), 83-107.

Espinosa, L. (2011). Pipelines and pathways: Women of color in undergraduate STEM majors and the college experiences that contribute to persistence. Harvard Educational Review, 81, 209-241.

Estrada, M., Woodcock, A., Hernandez, P., \& Wesley, P. (2011). Toward a model of social influence that explains minority student integration into the scientific community. Journal of Educational Psychology, 103(1), 206-222.

Flyvbjerg, B. (2006). Five misunderstandings about case-study research. Qualitative Inquiry, 12(2), 219-245.

Gaddis, M. (2013). The influence of habitus in the relationship between cultural capital and academic achievement. Social Science Research, 42(1), $1-13$.

Gasiewski, J., Tran, M., Herrera, F., Garcia, G., \& Newman, C. (2010). Barricades, bridges, and programmatic adaptation: A multi-campus study of STEM undergraduate research programs. Los Angeles: Higher Education Research Institute, University of California, Los Angeles.

Gazley, J., Remich, R., Naffzinger-Hirsch, M., Keller, J., Campbell, P., \& McGee, R. (2014). Beyond preparation: Identity, cultural capital, and readiness for graduate school in the biomedical sciences. Journal of Research in Science Teaching, 51(8), 1021-1048.

Gee, J. (2000). Identity as an analytic lens for research in education. Review of Research in Education, 25, 99-125.

Glaser, B., \& Strauss, A. (1965). Awareness of dying. New York: Aldine.

Griffin, K., Gibbs, K. D., Jr., Bennett, J., Staples, C., \& Robinson, T. (2015) "Respect me for my science": A Bourdieuian analysis of women scientists' interactions with faculty and socialization into science. Journal of Women and Minorities in Science and Engineering, 21(2), 159-179.

Hawks, B., \& Spade, J. (1998). Women and men engineering students: Anticipation of family and work roles. Journal of Engineering Education, 87(3), 249-256

Hazari, Z., Sadler, P., \& Sonnert, G. (2013). The science identity of college students: Exploring the intersection of gender, race, and ethnicity. Journal of College Science Teaching, 42(5), 82-91.

Hunter, A.-B., Laursen, S. L., \& Seymour, E. (2007). Becoming a scientist: The role of undergraduate research in students' cognitive, personal, and professional development. Science Education, 91(1), 36-74.

Hurtado, S., Cabrera, N., Lin, M., Arellano, L., \& Espinosa, L. (2009a). Diversifying science: Underrepresented student experiences in structured research programs. Research in Higher Education, 50(2), 189-214.

Hurtado, S., Han, J., Saenz, V., Espinosa, L., Cabrera, N., \& Cerna, O. (2009b). Predicting transition and adjustment to college: Biomedical and behavioral science aspirants' and minority students' first year of college. Research in Higher Education, 48(7), 841-887.

Jæger, M. (2011). Does cultural capital really affect academic achievement? New evidence from combined sibling and panel data. Sociology of Edu cation, 84(4), 281-298.

Lareau, A. (1987). Social class differences in family-school relationships: The importance of cultural capital. Sociology of Education, 60(2), 73-85.

Lareau, A. (2003). Unequal childhoods: Class, race and family life. Berkeley: University of California Press.

Lareau, A., \& Horvat, E. (1999). Moments of social inclusion and exclusion race, class, and cultural capital in family-school relationships. Sociology of Education, 72, 37-53.

Lareau, A., \& Weininger, E. (2003). Cultural capital in educational research: A critical assessment. Theory and Society, 32(5/6), 567-606.

Lave, J. (1991). Learning as participation in communities of practice. San Francisco: American Educational Research Association.

Lave, J., \& Wenger, E. (1991). Situated learning: Legitimate peripheral participation. Cambridge, UK: Cambridge University Press. 
Lee, J., \& Bowen, K. (2006). Parent involvement, cultural capital, and the achievement gap among elementary school children. American Educational Research Journal, 43(2), 193-218.

Mooney, G., \& Foley, D. (2011). Community colleges: Playing an important role in the education of science, engineering and health graduates (Info Brief, NSF 11-317). Arlington, VA: National Science Foundation.

Murphy, T., Gaughan, M., Hume, R., \& Moore, S. (2010). College graduation rates for minority students in a selective technical university: Will participation in a summer bridge program contribute to success? Educational Evaluation and Policy Analysis, 32(1), 70-83.

National Science Foundation. (2017). Louis Stokes Alliances for Minority Participation (LSAMP). Program Solicitation, NSF 17-579. Retrieved September 26, 2017, from www.nsf.gov/pubs/2017/nsf17579/nsf17579.htm

Ovink, S., \& Veazey, B. (2011). More than "getting us through": A case study in cultural capital enrichment of underrepresented minority undergraduates. Research in Higher Education, 52(4), 370-394.

Pender, M., Marcotte, D., Domingo, M., \& Maton, K. (2010). The STEM pipeline: The role of summer research experience in minority students' Ph.D. aspirations. Education Policy Analysis Archives, 18(30), 1-36.

Ritchie, J., \& Lewis, J. Jane (2003). Qualitative research practice: A guide for social science students and researchers. London: Sage.

Roscigno, V., \& Ainsworth-Darnell, J. (1999). Race, cultural capital, and educational resources: Persistent inequalities and achievement returns. Sociology of Education, 72(3), 158-178

Saldaña, J. (2009). The coding manual for qualitative researchers. London: Sage.

Seymour, E., Hunter, A.-B., Laursen, S. L., \& Deantoni, T. (2004). Establishing the benefits of research experiences for undergraduates in the sciences: First findings from a three-year study. Science Education, 88(4), 493534.

Shanahan, M-C. (2008). Identity in science learning: Exploring the attention given to agency and structure in studies of identity. Studies in Science Education, 45(1), 43-64.
Smith, B. (2018). Generalizability in qualitative research: Misunderstandings, opportunities and recommendations for the sport and exercise sciences. Qualitative Research in Sport, Exercise and Health, 10(1), 137-149.

Stake, R. (1995). The art of case study research. London: Sage.

Stanton-Salazar, R. (2010). A social capital framework for the study of institutional agents and their role in the empowerment of low-status students and youth. Youth and Society, 43(3), 1066-1109.

Starobin, S., Jackson, D., \& Laanan, F. (2013). Model programs for STEM student success at minority serving two-year colleges. In Palmer, R., Maramba, D., \& Gasman, M. (Eds.), Fostering success of ethnic and racial minorities in STEM: The role of minority serving institutions (pp. 59-71). New York: Routledge.

Stone, P. (2007). Opting out? Why women really quit careers and head home Berkeley: University of California Press.

Suddaby, R. (2006). From the editors: What grounded theory is not. Academy of Management Journal, 49(4), 633-642.

Sy, S., \& Romero, J. (2008). Family responsibilities among Latina college students from immigrant families. Journal of Hispanic Higher Education, 7(3), 212-227.

Tan, E., Barton, A., Kang, H., \& O'Neill, T. (2013). Desiring a career in STEM-related fields: How middle school girls articulate and negotiate identities-in-practice in science. Journal of Research in Science Teaching, 50, 1143-1179.

Thompson, J. J., Conaway, E., \& Dolan, E. L. (2016). Undergraduate students development of social, cultural, and human capital in a networked research experience. Cultural Studies of Science Education, 11(4), 959-990.

Trujillo, G., \& Tanner, K. (2014). Considering the role of affect in learning: Monitoring students' self-efficacy, sense of belonging, and science identity. CBE-Life Sciences Education, 13(1), 6-15.

Ward, K., \& Wolf-Wendel, L. (2004). Academic motherhood: Managing complex roles in research universities. Review of Higher Education, 27(2), 233-257.

White, J., \& Massiha, G. (2016). The retention of women in science, technology, engineering, and mathematics: A framework for persistence. International Journal of Evaluation and Research in Education, 5(1), 1-8. 